\title{
O TAMANHO CORPORAL DE CRIANÇAS E ADOLESCENTES: LIMITES AO DIREITO DE ESCOLHA
}

\author{
BODY SIZE OF CHILDREN AND ADOLESCENTS: LIMITS ON THE RIGHT TO CHOICE
}

Rafael de Oliveira Costa ${ }^{1}$ Leandro de Oliveira Costa ${ }^{2}$ Aline Martines Piroutek ${ }^{3}$

Resumo: A questão da obesidade e seu tratamento vem assumindo especial interesse das comunidades jurídica e científica. $O$ presente trabalho propõe, inicialmente, a existência de um "direito a ter qualquer tamanho corporal" como manifestação do direito ao livre desenvolvimento da personalidade. Contudo, diante da ausência de caráter absoluto, passa-se a investigar, também, a existência de limites a esse direito. Sustenta-se, assim, que ao verificar situações de obesidade mórbida que efetivamente impeçam crianças ou adolescentes de terem uma vida digna, com acúmulo anormal de gordura corporal, torna-se possível a intervenção do Ministério Público e do Poder Judiciário, por meio de demandas de internação compulsória e destituição do poder familiar, relativizando-se o "direito a ter qualquer tamanho corporal".

Palavras-chave: Direito à escolha do tamanho do próprio corpo. Destituição do poder familiar. Internação compulsória. Obesidade infantil.

\begin{abstract}
The issue of obesity and its treatment has been taking on particular interest from the legal and scientific communities. Reflecting extensive bibliographical research, the present work initially proposes the existence of a "right to have any body size" as a manifestation of the right to free development of personality. Yet, when verifying situations of morbid obesity that effectively prevent children and adolescents from living a dignified life with an abnormal accumulation of body fat, it becomes necessary an intervention of the Public Prosecutor's Office and the Judiciary, through compulsory hospitalization and destitution of "family power".

Keywords: Right to choose the body size. Destitution of family power. Compulsory hospitalization. Childhood obesity.
\end{abstract}

Recebido em 24 de abril de 2016 Avaliado em 21 de junho de 2016 (AVALIADOR A) Avaliado em 16 de julho de 2017 (AVALIADOR B) Avaliado em 13 de julho de 2017(AVALIADOR C) Aceito em 13 de junho de 2019

\footnotetext{
1 Doutor e Mestre em Direito pela Faculdade de Direito da Universidade Federal de Minas Gerais; Graduado em Direito pela Faculdade de Direito da Universidade Federal de Minas Gerais, em programa conjunto com a University of Wisconsin-Madison (Estados Unidos); Professor na Escola Superior do Ministério Público; Professor Visitante na Universidade da Califórnia-Berkeley; Promotor de Justiça no Estado de São Paulo (Rua Treze de Maio, 1259, Bela Vista, 01327-001, São Paulo, São Paulo, Brasil); https://orcid.org/0000-0001-9979-9382; rafaelcosta22000@gmail.com

2 Mestre e Graduado em Medicina pela Universidade Federal de Minas Gerais; https://orcid.org/0000-0002-7468-5669; leandro.3415@gmail.com

3 Pós-doutora pela Universidade Estadual de Campinas; Doutora e Mestre em Estatística pela Universidade Federal de Minas Gerais; Graduada em Ciências Atuariais pela Universidade Federal de Minas Gerais; Professora Visitante na Universidade da Califórnia-Berkeley; https://orcid.org/0000-0003-3721-681X; lyne.piroutek@yahoo.com.br
} 


\section{Introdução}

A abordagem tradicionalmente dada à temática da obesidade parte do pressuposto de que é uma moléstia atrelada a distúrbios metabólicos e aspectos psíquicos e sociais, devendo-se, sob a ótica jurídica, tratar com respeito o portador da doença (vedação à discriminação).

Refletindo extensa pesquisa bibliográfica, o presente trabalho propõe uma ruptura com essa visão tradicional, sustentando a existência de um "direito a ter qualquer tamanho corporal" como manifestação do direito ao livre desenvolvimento da personalidade. Trata-se, em verdade, de compreender e tratar juridicamente a obesidade como resultante do contraste entre a programação genética, o ambiente obesogênico atual e os aspectos bioculturais envolvidos. ${ }^{4}$

Contudo, diante do fato de que o "direito ao tamanho corporal" não tem caráter absoluto, torna-se indispensável investigar, também, quais são os seus limites. Nesse liame, os mais recentes estudos na área médica demonstram que os pais desempenham papel primordial no controle e tratamento da obesidade, ao supervisionarem a ingestão alimentar e a realização de atividades físicas dos filhos, notadamente quando capazes de estabelecer um diálogo acerca dos males dela decorrentes.

Assim, ao verificar situações de obesidade mórbida que efetivamente impeçam crianças e adolescentes de terem uma vida digna, torna-se necessária a intervenção do Ministério Público e do Poder Judiciário, por meio de demandas de internação compulsória e destituição do poder familiar.

Esse o nosso plano de estudos. Passemos à sua concretização.

\section{Do direito ao tamanho do próprio corpo}

Segundo Heidegger, pessoa não é coisa ou objeto: é unidade de corpo, alma e espírito, transitando e interagindo com o mundo que a rodeia, com os outros seres humanos e com a sua própria individualidade, em um permanente "tornar-se" (HEIDEGGER, 2006). Para dizer de outro modo, a pessoa humana não apenas compreende os fatos a partir de seus horizontes, mas faz parte deles. "E é neste possuir mundo que o ser humano é transexistencial." (HEIDEGGER, 2006, p. 168).

Com efeito, cada ser humano é, a um só tempo, os "muitos seres" que o existir permite. A dignidade humana resulta "[...] dessa possibilidade de uma existência pluridimensional e em transição; uma existência plúrima em potencialidades, ainda que finita." (OLIVEIRA, 2013, p. 13). Finitude (morte), esta, que não desconsidera a condição humana como ser em constante construção (OLIVEIRA, 2013).

Assim, Heidegger desloca a questão do ser para uma nova ontologia, na qual é pensado não mais como ente absoluto, mas, sim, enquanto abertura interpretativa limitada pela própria condição humana (MEGALE, 2007). Em outras palavras, a consciência transcendental desvincula-se dos

\footnotetext{
4 Sobre o tema, conferir: Lytle, Kubik e Perry (2006, p. 8-13).
} 
objetos do mundo empírico, apesar de não os ignorar na tarefa da compreensão (COSTA, 2009). A própria noção de personalidade enseja, a partir desses pressupostos, um ideal de liberdade, autonomia e individualidade. Busca-se tutelar a identidade da pessoa - sob o aspecto de sua materialidade física e seu âmbito psíquico -, bem como o seu modo de pensar e a forma de "estar no mundo".

A personalidade, contudo, não reflete um direito propriamente dito, mas verdadeira cláusula geral que serve de substrato para os direitos que dela emanam. ${ }^{5}$ Os direitos da personalidade vinculam-se ao ser de maneira permanente, resguardando não apenas atributos físicos, psíquicos e morais, mas também a projeção da pessoa na sociedade (GAGLIANO; PAMPLONA FILHO, 2006, p. 135). Refletem, em verdade, "bens ou valores essenciais da personalidade" (AMARAL, 2003, p. 249), que englobam aspectos físicos (v.g., o direito à vida, ao próprio corpo, à integridade física e estética), intelectuais (v.g., direito moral do autor e do inventor pelo objeto da criação), e morais (v.g., direito à liberdade, à honra, ao recato, segredo, imagem e respeito).

Nesse liame, o direito ao livre desenvolvimento da personalidade permite a cada um escolher o seu modo de vida, sem a intervenção de outrem ou do Estado. Trata-se de expressão da liberdade e que apresenta um aspecto positivo - liberdade de agir - e um negativo - não interferência na vida alheia (MOTA PINTO, 1999). Neste último aspecto, reflete também um "dever prestacional" do Estado, que deve disponibilizar meios para que a pessoa desenvolva sua personalidade da forma que melhor the aprouver (MOTA PINTO, 1999). O art. 22, da Declaração Universal dos Direitos do Homem de 1948, dispõe que toda pessoa, como membro da sociedade, tem direito à realização dos direitos individuais, econômicos, sociais e culturais indispensáveis à sua dignidade e ao livre desenvolvimento da sua personalidade.

Dentre as diversas manifestações do livre desenvolvimento da personalidade, interessa neste trabalho o que se convencionou chamar de "direito ao próprio corpo". ○ "direito ao próprio corpo" tutela, de um modo geral, a liberdade de o indivíduo não sofrer violações ou ofensas. Isso porque o corpo é o meio pelo qual a pessoa realiza a sua missão no mundo e exerce a sua liberdade. Abrange, portanto, a integralidade, as partes destacáveis e a forma escolhida para vivenciar o próprio corpo, ${ }^{6}$ uma vez que reflete a autonomia do ser e a sua liberdade-no-mundo.

O direito ao corpo deve ser compreendido finalisticamente, ou seja, como base de toda a experiência do ser. $O$ corpo assume não só um papel fundamental no modo como percebemos e experimentamos o mundo, mas também na formação de significados, no relacionamento com outros seres e na construção do sentido do "Eu". É impossível fazer juízos de valor sobre "o tamanho corporal" desconectados da experiência do ser-no-mundo: mente e corpo estão intimamente ligados à

5 Daí porque a dignidade da pessoa humana "só pode ser entendida como fórmula vazia, adaptável a todos os conteúdos." (ASCENSÃO, 2006, p. 153).

6 "No conceito de proteção à integridade física inscreve-se o direito ao corpo, no que se configura a disposição de suas partes, em vida ou para decisão da morte, para finalidades científicas ou humanitárias, subordinando conteúdo à preservação da própria vida ou de sua deformidade." (PEREIRA, 2008, p. 250). 
própria compreensão do "Eu". Por este motivo, o ordenamento jurídico deve ser capaz de açambarcar a singularidade de cada corpo e garantir à pessoa humana liberdade de vivenciar o existir em sua plenitude.

Assim, partindo do direito ao livre desenvolvimento da personalidade e atentando para o fato de que o rol de direitos fundamentais apresentado pela Constituição não exclui outros decorrentes do regime e dos princípios por ela adotados (artigo $5^{\circ}, \mathbb{S} 2^{\circ}$ ), não se pode ignorar a existência do "direito à escolha do tamanho corporal". ${ }^{8}$ Isso porque, no cerne do direito à liberdade e do "dever prestacional" do Estado ao livre desenvolvimento da personalidade encontra-se um campo inexplorado, que tangencia o direito de cada um de determinar a própria existência: o reino do tamanho do corpo (TIROSH, 2012, p. 266). Ao tentar fazer alguém mudar seu tamanho corporal acaba-se, em verdade, por estimulá-lo a transformar a sua própria noção de "Eu" e a forma como experimenta o mundo (TIROSH, 2012, p. 306).

À primeira vista, pode parecer um contrassenso defender a existência do direito fundamental à escolha do tamanho do próprio corpo, em razão da ausência de respaldo constitucional. Contudo, trata-se de manifestação do direito à liberdade de cada um de se ver livre de intervenções sociais ou governamentais em relação ao peso do corpo. $O$ tamanho do corpo é digno de proteção em si mesmo, em razão de seu papel fundamental no desenvolvimento e manutenção da identidade e da personalidade, ${ }^{9}$ razão pela qual dotado de um aspecto negativo e um aspecto positivo.

$\mathrm{O}$ aspecto negativo se refere ao direito à autonomia, à dignidade e à liberdade, porque exige essencialmente que o governo ou outros atores sociais se abstenham de intervir na vida das pessoas com fulcro no tamanho do corpo; "o tamanho do corpo de uma pessoa, seja ela pequena ou voluptuosa, deve ser irrelevante para a relação entre o cidadão e o Estado." (TIROSH, 2012, p. 314).

De outro modo, o direito à escolha do tamanho corporal também possui um aspecto positivo: o ordenamento jurídico deve garantir que as mesmas oportunidades sejam asseguradas a pessoas que têm diferentes tamanhos corporais. Exemplificativamente, os espaços físicos destinados a acomodar pessoas - como as camas em que atendem os médicos ou os assentos de teatros e aviões -, devem comportar os vários tamanhos de corpos existentes, evitando que uma pessoa tenha "que pagar por dois lugares" (TIROSH, 2012, p. 318).

Assim, ao estabelecer políticas que pretendam reduzir o âmbito de liberdade de pessoas obesas, o Administrador Público deve considerar o tamanho do corpo não apenas sob o pálio médicocientífico, mas também sob uma perspectiva humanista, que compreende a pessoa como um fim em si mesma e que atente para a singularidade da experiência de cada um (TIROSH, 2012, p. 355).

\footnotetext{
7 "A legal system that fails both to appreciate the uniqueness of literally everybody and to allow its subjects the freedom to live their lives with their own, special, intimate bodily texture (which is both a product of who they are and makes them who they are) is a legal system that cannot claim to be based on the liberal premise of respect for basic liberty, autonomy, and dignity." (TIROSH, 2012, p. 308).

8 Sobre o direito à escolha do tamanho do próprio corpo e do direito de ser obeso, conferir também: Kirkland (2008, p. 397425). E também: Ramachandran (2009).

9 Sustenta o autor que "The central rationale behind the right to be fat is that sending a direct or an indirect message to a fat person that he or she needs to lose weight in order to gain access to various social goods, such as equal opportunity, dignity, and autonomy, is no less intrusive than telling a legal subject how to think, what to believe, or what to say." (TIROSH, 2012, p. 314).
} 
Ao contrário do que vem sendo tradicionalmente objeto de análise pela doutrina, a vedação à discriminação representa apenas um dos aspectos do direito ao corpo que demanda atenção da comunidade jurídica.

Na tutela do consumidor, por exemplo, as companhias que efetuam a venda de produtos destinados a obesos apenas via internet - para evitar denegrir a imagem da marca junto aos "consumidores regulares" - estão, em verdade, realizando simbólica exclusão coletiva (TIROSH, 2012, p. 317).

Do mesmo modo, na seara do Direito Civil, a celebração de acordos pré-nupciais que incluem como condição do casamento que a esposa "não venha a engordar" refletem, também, violação ao exercício do direito ao tamanho do próprio corpo.

Em verdade, a obesidade tornou-se sinônimo de "cidadãos de segunda classe", como se a vida de uma pessoa que possui alguns quilos a mais valesse menos do que a daqueles que têm o peso considerado "normal" (TIROSH, 2012, p. 317).

Não se ignora o fato de que a obesidade seja tida como uma doença atrelada a distúrbios metabólicos. Contudo, a sua natureza fisiológica não pode transcender a dimensão da escolha individual. Diante das recentes conquistas na seara da Bioética - que assentou o princípio da autonomia do paciente - e do Biodireito - que encampou o princípio da autonomia da vontade -, não é possível impor à pessoa um tratamento a que não deseje se submeter.

Assim, embora a obesidade possa não decorrer somente de uma escolha, mas também de condições genéticas ou bioculturais, a opção por não se submeter a qualquer tratamento v.g., cirurgia bariátrica, reeducação alimentar, entre outros - deve decorrer da autonomia como dimensão da liberdade do paciente, ou seja, verdadeiro desdobramento do "livre desenvolvimento da personalidade". A título meramente exemplificativo, se o paciente de câncer em estado terminal pode fazer a opção por não receber qualquer espécie de tratamento, porque não é possível garantir à pessoa obesa o seu autogoverno? Do mesmo modo, se o médico pode deixar de fazer uso de meios artificiais para manter a vida em caso de doença grave irreversível, desde que haja consentimento do paciente (ortotanásia), por que motivo deve-se inviabilizar, àquele que está em pleno exercício de suas faculdades mentais, o direito à escolha do tamanho corporal?

Sob essas perspectivas, qualquer restrição ao direito ao livre desenvolvimento da personalidade e, por via de consequência, ao direito à escolha do tamanho do próprio corpo, só se torna possível quando não violar o núcleo intangível do âmbito de proteção das normas constitucionais e infraconstitucionais que regulamentam a matéria. Quais seriam esses limites no âmbito da Infância e Juventude?

É o que passaremos a responder nos próximos tópicos. 


\section{Da obesidade na infância e adolescência como fator de prognóstico negativo e suas implicações psicossociais}

Hodiernamente, em que pesem os diversos tratamentos existentes para a obesidade, o estilo de vida compromete não só a aderência, mas também a permanência do paciente.

Conforme veem demonstrando os mais recentes estudos, o Índice de Massa Corporal (IMC) é fator de risco e está diretamente relacionado com a redução da expectativa de vida. ${ }^{10}$ Em outras palavras, quando o IMC ultrapassa 25, o índice de mortalidade cresce proporcionalmente. Ademais, a obesidade, quando associada a agravos como diabete melittus, infarto do miocárdio, doença renal crônica, dentre outras, pode contribuir para o aumento do índice de mortalidade (ADAMS, 2006, p. 355). Até mesmo pessoas diagnosticadas com câncer apresentam, quando obesas, taxas de mortalidade superiores (ADAMS, 2006, p. 355).

Assim, dúvida não há acerca da necessidade de intensificação das campanhas de controle de peso. As políticas de saúde pública devem, preservado o direito à escolha do tamanho corporal de cada um, instruir a população de que a obesidade não se limita a questões estéticas. Trata-se de agravo com implicações importantes não só no desenvolvimento do ser humano, mas também na incidência de inúmeras comorbidades. Entre os adolescentes, obeso era, até algum tempo atrás, apenas aquele que apresentava IMC superior a 25. Na atualidade, contudo, os trabalhos científicos classificam como obesos adolescentes que apresentam índice de massa corporal igual ou superior ao percentil 95\% para a idade e sexo (HEDLEY, 2004, p. 2847-2850). Seguindo esse padrão, enquanto a prevalência de obesos no mundo gira em torno de 16\% (HEDLEY, 2004, p. 2847-2850), no Brasil, o IBGE atesta que, em 2009, esse índice era 16,6\%, atingido a marca de 24\% em 2013. ${ }^{11}$ Entre crianças e adolescentes, acredita-se que aproximadamente $50 \%$ são obesos ou serão obesos quando adultos, tornando-os, indubitavelmente, um grupo de risco. O número se torna ainda mais alarmante quando se percebe que, nas últimas três décadas, o número de adolescentes obesos triplicou (NEAD, 2004, p. 104-108).

Infelizmente, os estudos acerca dos fatores de risco na primeira infância que levam a possíveis ações de prevenção da epidemia de obesidade infantil são incompletos. ${ }^{12}$ As estratégias de prevenção existentes, focadas no final da infância e da adolescência, geralmente são malsucedidas pelo fato de que o "comportamento alimentar" já foi estabelecido quando o paciente era ainda mais jovem. ${ }^{13}$

Uma vez que não existe uma única causa da obesidade infantil, pode-se focá-la em seus múltiplos níveis (v.g., genético, celular, fisiológico, psicológico, social e cultural) e esferas de influência (criança, família, comunidade e país) em busca de padrões (DEV et al., 2013, p. 399-408). Como resultado de análises inferenciais estatísticas, dos vinte e dois fatores de risco, três deles são significativamente

\footnotetext{
$\overline{10}$ Por todos, conferir: Gu et al. (2006, p. 776-783).

11 http://www.ibge.gov.br/home/.

12 Sobre o tema, conferir: Koplan (2007).

13 Conferir Birch e Ventura (2009, p. 74-81).
} 
associados ao sobrepeso e obesidade infantil: duração do sono noturno, IMC (índice de massa corporal) dos pais e a ausência de restrição às práticas alimentares (DEV et al., 2013, p. 399-408).

Nesse contexto, a obesidade entre crianças e adolescentes deve ser analisada não apenas como causa, mas também como consequência de implicações psicossociais (GOODMAN, 2002, p. 497-504). Enquanto processos agravadores, podemos citar a depressão, a ausência de limites comportamentais, o estresse emocional e o preconceito social (GOODMAN, 2002, p. 497-504). A título de exemplo, a depressão pode levar ao isolamento social, à negligência em relação à aparência, desânimo em realizar atividades físicas e aumento da ingestão alimentar, circunstâncias que, somadas, contribuem sensivelmente para o aumento do peso (GOODMAN, 2002, p. 497-504).

Da mesma forma, em países desenvolvidos já se constatou que o baixo poder aquisitivo leva à inacessibilidade às atividades esportivas e ao consumo de alimentos de baixo custo, normalmente com alto teor calórico, fatores que, associados à falta de instrução dos responsáveis legais, contribuem para obesidade na infância e juventude (GOODMAN, 2002, p. 497-504).

Além disso, o estresse emocional, causado pelo divórcio ou o falecimento de entes queridos também pode ocasionar atitudes de superalimentação (SCHNEIDER, 2013, p. 618-715).

Não bastasse, o estresse crônico, ao alterar a qualidade do sono, leva também à fadiga diurna e à relutância na prática de atividades físicas de modo regular, contribuindo para o ganho de peso (SCHNEIDER, 2013, p. 618-715).

A preocupação excessiva com a aparência gera, em crianças e adolescentes, medo em se exporem, inibindo a prática de atividades físicas e contribuindo para o sobrepeso. Vale mencionar que recente estudo realizado com adolescentes entre 8 e 18 anos constatou que os obesos apresentavam menor motivação para realização de atividades físicas e maior ingestão alimentar, aumentando as chances de desenvolverem depressão e ansiedade em 2,8 e 2,5 vezes, respectivamente, quando comparados com a aqueles que a presentavam peso considerado "normal" (ANDERSON, 2007, p. 740747). E mais: quanto maior o período em que o adolescente permanece obeso, maior a probabilidade de desenvolver depressão (HASLER, 2005, p. 842-850).

Contatou-se, ademais, que a obesidade ainda aumenta as taxas de alteração de humor, implica em distúrbios alimentares e reduz a satisfação com a qualidade de vida, sem mencionar o fato de que a chance de o adolescente desenvolver baixa autoestima amplia 1,44 vez (WANG, 2008, p. 615-623).

No mesmo sentido, trabalho publicado na Paediatric Child Health revelou que adolescentes obesos têm maiores chances de se sentirem irritados, especialmente diante da maior prevalência de apneia durante o sono (NIEMAN, 2012, p. 205-206), e que, adotado como parâmetro dez libações alcoólicas para avaliar o aumento do consumo de álcool entre adolescentes, os obesos apresentaram uma taxa significativamente superior quando comparados com aqueles que apresentam IMC considerado "normal" (5,3\% e 2,4\%, respectivamente) (NIEMAN, 2012, p. 205-206). 
Em síntese, enquanto causa de implicações psicossociais, a obesidade contribui para o aparecimento de distúrbios psicológicos e psiquiátricos, baixa autoestima, redução na qualidade de vida, consumo de álcool e até suicídio entre aqueles que não atingiram a maioridade.

\title{
3 Relativizando o direito à escolha do tamanho do corpo: da possibilidade destituição do poder familiar e internação compulsória de crianças e adolescentes
}

\author{
Conforme ressaltado anteriormente, o tamanho do corpo é digno de proteção em si
} mesmo, em razão de seu papel fundamental no desenvolvimento e manutenção da identidade e da personalidade (TIROSH, 2012, p. 314). ${ }^{14}$ Não se trata, contudo, de direito absoluto. Quais seriam os seus limites?

Em primeiro lugar, é preciso perceber que os direitos públicos subjetivos à saúde e à alimentação representam prerrogativas jurídicas indisponíveis asseguradas à generalidade das pessoas. ${ }^{15}$ Refletem bens jurídicos constitucionalmente tutelados, devendo o Poder Público velar, de maneira responsável, pela formulação e implantação de políticas sociais e econômicas idôneas que visem a garantir, a crianças e adolescentes, especialmente àqueles portadores de obesidade, o acesso universal e igualitário à assistência farmacêutica, médico-hospitalar e à alimentação adequada. ${ }^{1617}$

\footnotetext{
14 Sustenta o autor que "The central rationale behind the right to be fat is that sending a direct or an indirect message to a fat person that he or she needs to lose weight in order to gain access to various social goods, such as equal opportunity, dignity, and autonomy, is no less intrusive than telling a legal subject how to think, what to believe, or what to say." (TIROSH, 2012, p. 314).

15 Dispõe o artigo $6^{\circ}$, da Constituição, que "São direitos sociais a educação, a saúde, a alimentação, o trabalho, a moradia, o lazer, a segurança, a previdência social, a proteção à maternidade e à infância, a assistência aos desamparados, na forma desta Constituição." A previsão expressa da alimentação e da saúde no artigo 6º da Constituição, reforça a exigibilidade desses direitos, seja perante a própria administração pública, seja perante o Judiciário. Trata-se de autênticos direitos sociais, que não podem ser destituídos de eficácia.

No que concerne à alimentação, a Constituição não tratou de assegurar qualquer modalidade de nutrição. A Lei Orgânica de Segurança Alimentar e Nutricional (Lei Federal n 11.346/06), aprovada pelo Congresso Nacional e sancionada pelo Presidente da República no dia 15 de setembro de 2006, institui o Sistema Nacional de Segurança Alimentar e Nutricional - SISAN com vistas a assegurar o direito fundamental à alimentação adequada, dispondo, em seu artigo $2^{\circ}$, que: "A alimentação adequada é direito fundamental do ser humano, inerente à dignidade da pessoa humana e indispensável à realização dos direitos consagrados na Constituição Federal, devendo o poder público adotar as políticas e ações que se façam necessárias para promover e garantir a segurança alimentar e nutricional da população."

O direito fundamental à alimentação adequada abrange alimentos seguros e saudáveis, em quantidade e qualidade adequadas e suficientes. A alimentação, portanto, não deve pode ser desmensurada ou fruto de puro hedonismo, mas deve se conformar com as necessidades de cada pessoa, em qualidade e quantidades adequadas e suficientes.

Frise-se que o direito à saúde é um direito de todos, constituindo um dever do Estado sua efetivação (art. 196, da Constituição), razão pela qual está intimamente relacionado com a ideia de vida com dignidade e possui natureza indisponível. Contudo, o direito à saúde - como ocorre com qualquer outro - pode ser relativizado. Assim, é preciso que os poderes públicos levem à sério a concretização desse direito fundamental e ofereçam serviços de saúde e alimentação de qualidade a toda a população, implementando políticas públicas voltadas para conscientização dos riscos da obesidade, sem violar a liberdade de cada um. Isso porque, até mesmo os direitos previstos na Constituição encontram-se condicionados pela historicidade. E é desta correlação entre ser e dever ser que decorrem as possibilidades e os limites da força normativa da Constituição e a busca perpétua pela efetividade dos direitos à adequada alimentação e à saúde.

16 Sobre o tema, conferir: Silva e Terrazas (2011, p. 825-853). Frise-se, por oportuno, que a Lei Federal n $8.080 / 90$ não destoa dos preceitos constitucionais e estabelece, em seu artigo $2^{\circ}$, a responsabilidade estatal pela adequada prestação de serviços de saúde às pessoas.

17 Nesse sentido, a Recomendação n 67/18, do CNMP, estabelece que: "Art. $1^{\circ}$ Recomendar aos membros do Ministério Público da União e dos Estados, dentro do limite de suas atribuições, que realizem ações de prevenção e combate à obesidade infantil, notadamente: I - que desenvolvam ações de monitoramento e fiscalização do cumprimento por parte dos estabelecimentos comerciais e por órgãos públicos da Norma Brasileira de Comercialização de Alimentos para Lactentes e Crianças de Primeira Infância, Bicos, Chupetas e
} 
Ora, um Estado que se propõem a cumprir tais objetivos deve criar condições que permitam e favoreçam o desenvolvimento livre e integral da pessoa e da vida digna, o que implica, dentre outras coisas, a promoção, a defesa e a recuperação da saúde individual e coletiva. Assim como ocorre com o direito ao livre desenvolvimento da personalidade, o caráter programático das normas mencionadas não pode converter-se em promessas vãs, sob pena de o Poder Público, fraudando as expectativas nele depositadas pela coletividade, substituir, de maneira ilegítima, o cumprimento de seu dever por um gesto irresponsável de infidelidade constitucional (ALEXY, 2008).

A dificuldade, conforme ressaltamos anteriormente, está em estabelecer o âmbito intangível de proteção do direito à escolha do tamanho corporal e quais atos referentes à autonomia privada podem ser objeto de regulamentação pelo Poder Público.

Buscando a adequada exegese das normas que regem a matéria e atentando para o fato de que a reprodução mecânica de listas de princípios e métodos de interpretação pode implicar em mera panaceia, entendemos que, ao verificar situações de obesidade mórbida envolvendo crianças ou adolescentes, faz-se necessária a intervenção estatal, especialmente quando os responsáveis legais não desempenham adequadamente a função de supervisionarem a ingestão alimentar e a realização de atividades físicas.

Não se alegue que a internação compulsória de crianças e adolescentes portadoras de obesidade mórbida implica (especialmente quando não conseguem sequer deixarem uma cama) em indevida intromissão no direito à escolha ao tamanho do próprio corpo. A renúncia ao direito à vida (digna) confere legitimidade à intervenção estatal na esfera de autonomia da vontade daqueles que não ostentam capacidade de fato, fazendo valer o direito ao livre desenvolvimento da personalidade. Ao consumir produtos que venham a prejudicar o organismo, a pessoa o faz dentro da sua esfera de liberdade. Contudo, quando o exercício de tal liberdade chega a colocar em risco a própria existência, a intervenção estatal passa a ser legítima em relação aos incapazes. E a conclusão a que chegamos é que, de fato, a autonomia da vontade encontra limite no livre desenvolvimento da personalidade de crianças e adolescentes, em virtude da incapacidade de fato que ostentam. Em assim sendo, ao contrário do que ocorre com as pessoas dotadas de capacidade - que têm ampla liberdade de escolherem o tamanho do próprio do corpo, com fulcro, inclusive, no princípio do Biodireito da autonomia -, o desrespeito ao corpo condena crianças e adolescentes portadores de obesidade aos

\footnotetext{
Mamadeiras (NBCAL), definida pela Lei $n^{\circ} 11.265$ de 3 de janeiro de 2006 e regulamentada pelo Decreto no 8.552, de 3 de novembro de 2015, bem como estímulos a ações municipais e estaduais de promoção do aleitamento materno; II - que promovam ações de monitoramento e fiscalização do cumprimento do Código de Defesa do Consumidor, da Resolução Conanda no 163/2014 e do compromisso pela publicidade saudável para crianças de evitar a publicidade abusiva direcionada a crianças e adolescentes, inclusive, mas não exclusivamente, em ambientes escolares; III - incentivem e promovam ambientes escolares saudáveis, em parceria com gestores públicos, escolas, pais e alunos, desenvolvendo ações que envolvam a proibição de publicidade de alimentos e bebidas não saudáveis, desestímulo ou proibição de vendas ou ofertas de produtos industrializados ou ultraprocessados nos refeitórios e cantinas escolares e incentivando a aquisição e oferta de alimentos in natura e orgânicos, de acordo com as recomendações do Programa Nacional de Alimentação Escolar - PNAE, com o manual de cantinas saudáveis e como Guia Alimentar da População Brasileira do Ministério da Saúde."
} 
males de suas enfermidades, implicando em riscos à saúde, suscetível, pois, de correção pelo Poder Judiciário, em virtude da situação de vulnerabilidade em que se encontram.

Pondere-se que não se está a defender aqui a intervenção desmensurada do Estado, como na hipótese de "sobrepeso moderado", que deve implicar no adequado acompanhamento e aconselhamento pela rede municipal. O que não se pode admitir é a ausência de intervenção diante de casos de obesidade mórbida, decorrentes de transtorno mental ou efetivo abandono de crianças e adolescentes pelos genitores.

Cabe observar que a dignidade da pessoa humana é hoje entendida sob múltiplas perspectivas - ontológica, histórico-cultural, assistencial e relacional -, apresentando uma dimensão defensiva e uma dimensão prestacional. Na primeira, tem-se verdadeiro dever de abstenção pelo Estado. Na segunda esfera, como tarefa imposta a toda sociedade, reclama que entes públicos guiem suas ações não só no sentido de preservar a dignidade existente, mas também no sentido de promovêla. Na lição de Ingo Wolfgang Sarlet (2009, p. 55):

Fechado o parêntese e na perspectiva já sinalizada (dignidade como limite e tarefa), sustenta-se que uma dimensão dúplice da dignidade manifesta-se enquanto simultaneamente expressão da autonomia da pessoa humana (vinculada à idéia de autodeterminação no que diz com as decisões essenciais a respeito da própria existência), bem como da necessidade de sua proteção (assistência) por parte da comunidade e do Estado, especialmente quando fragilizada e até mesmo e principalmente quando ausente a capacidade de autodeterminação. Assim, a dignidade, na sua perspectiva assistencial (protetiva) da pessoa humana, poderá, dadas as circunstâncias, prevalecer em face da dimensão autonômica.

Assim, nas hipóteses de obesidade classe III, ${ }^{18}$ em que a criança ou o adolescente doente não possui controle sobre a sua vida, deteriorando diariamente a sua saúde e causando transtornos

$\overline{18}$ O grau de obesidade é normalmente classificado em três categorias: obesidade leve (classe 1 - IMC 30 a $34,9 \mathrm{~kg} / \mathrm{m}^{2}$ ), moderada (classe 2 - IMC35 a 39,9 kg/m²) e grave ou mórbida (classe 3 - IMC $\geq 40 \mathrm{~kg} / \mathrm{m}^{2}$ ). 
à sociedade e às pessoas, torna-se possível, a partir de laudo médico circunstanciado, a devida intervenção do Ministério Público. ${ }^{19,20}$

Não bastasse, a negligência reiterada dos pais na saúde e no controle do peso dos filhos torna possível até mesmo a destituição do poder familiar. Nesse sentido, os tribunais norteamericanos têm destituído genitores com fulcro no excesso de peso de crianças submetidas a dietas desarrazoadas. $O$ peso dos filhos é usualmente considerado como indicativo de negligência e abuso dos pais, que deixam de prestar os cuidados alimentares necessários à prole. ${ }^{21}$

No Brasil, estabelece o artigo 1.638, incisos II e III, do Código Civil, que: "Artigo 1.638 - Perderá por ato judicial o poder familiar o pai ou a mãe que: II - deixar o filho em abandono; III praticar atos contrários à moral e aos bons costumes."

Conforme se depreende do dispositivo em apreço, ao praticarem atos contrários à moral e aos bons costumes, imprimindo dieta inescrupulosa aos filhos, negligenciando, ainda, a atenção básica, dúvida alguma existe acerca da necessidade do ajuizamento pelo Ministério Público de demanda de destituição do poder familiar. Ora, o abandono priva os filhos do direito à convivência familiar, além de prejudicar-lhes a saúde e o livre desenvolvimento. Assim, a falta de assistência material e a imposição de dieta que invariavelmente conduz à obesidade mórbida, coloca em risco a sobrevivência dos infantes, permitindo a intervenção estatal.

Ademais, o inciso III do dispositivo legal em tela admite interpretação ampliativa, abrangendo a conduta violadora da moral sob diversos aspectos, incluindo o alcoolismo, a vadiagem,

\footnotetext{
19 A Constituição, em seu artigo 129, inciso II, estabelece que ao Ministério Público compete zelar pelo efetivo respeito aos direitos assegurados na Carta Magna, promovendo as medidas necessárias às suas garantias. No mesmo sentido, o artigo 197 dispõe que "são de relevância pública as ações e serviços de saúde." No tocante à tutela dos direitos das crianças e dos adolescentes, cumpre ressaltar o disposto no artigo 227, da Constituição Federal: "É dever da família, da sociedade e do Estado assegurar à criança e ao adolescente, com absoluta prioridade, o direito à vida, à saúde, à alimentação, à educação, ao lazer, à profissionalização, à cultura, à dignidade, ao respeito, à liberdade e à convivência familiar e comunitária, além de colocá-los a salvo de toda forma de negligência, discriminação, exploração, violência, crueldade e opressão."

Note-se que os dispositivos constitucionais são contundentes em relação à obrigação imposta ao Estado de resguardar o direito à saúde e à vida de todos os brasileiros, priorizando-se, no entanto, à infância.

A Lei Federal n 8.069/90 (Estatuto da Criança e do Adolescente) em seu artigo 4º, prevê que: "É dever da família, da comunidade, da sociedade em geral e do Poder Público assegurar, com absoluta prioridade, a efetivação dos direitos referentes à vida, à saúde, à alimentação, à educação, ao esporte, ao lazer, à profissionalização, à cultura, à dignidade, ao respeito, à liberdade e à convivência familiar e comunitária."

O artigo 11 dispõe que: "É assegurado atendimento médico à criança e ao adolescente, através do Sistema Único de Saúde, garantido o acesso universal e igualitário às ações e serviços para promoção, proteção e recuperação da saúde."

Em se tratando de direitos individuais indisponíveis, o Ministério Público está legitimado para a defesa da vida, da saúde e da alimentação, a teor do que dispõe o artigo 127, in fine, da Constituição. E mais: incumbe ainda ao Ministério Público instaurar inquérito civil e propor as ações civis públicas pertinentes na defesa dos interesses transindividuais relacionados à proteção das pessoas portadoras de obesidade. Assim, havendo interesses transindividuais que digam respeito ao direito ao tamanho corporal, o Ministério Público está plenamente autorizado pela Constituição e pela legislação infraconstitucional a instaurar inquérito civil para investigar a ocorrência de eventuais violações às normas protetivas, objetivando a análise da necessidade de propositura das medidas cabíveis.

20 Note-se que, com o advento da Lei Federal 10.216, de 06 de Abril de 2001, que dispõe sobre a proteção e os direitos das pessoas portadoras de transtornos mentais, a internação deve ser adotada como medida excepcional, só determinada quando se mostrarem insuficientes os recursos extra hospitalares e mediante laudo médico circunstanciado que caracterize os seus motivos. Assim, na hipótese de obesidade mórbida reconhecida por meio de laudo pericial, a existência de transtorno, apto a caracterizar a necessidade de tratamento, flexibiliza a autonomia da vontade do obeso, visto que a liberdade deve ceder espaço a direito preponderante (direito à saúde).

21 Sobre o tema, vale à pena conferir: Garrahan e Eichner (2012).
} 
a mendicância, o uso de substâncias entorpecentes, a prática da prostituição e até mesmo a adoção de vida desregrada e que implica em risco à saúde de crianças e adolescentes. Assim, ao não assumirem responsabilidades quanto à criação dos filhos, os genitores dão ensejo à necessidade de intervenção estatal para sanar situações de obesidade mórbida. Nesse sentido, dispõe o artigo $5^{\circ}$, do Estatuto da Criança e do Adolescente: "Artigo $5^{\circ}$ - Nenhuma criança ou adolescente será objeto de qualquer forma de negligência, discriminação, exploração, violência, crueldade e opressão, punido na forma da lei qualquer atentado, por ação ou omissão, aos seus direitos fundamentais."

Em suma, ao omitirem por diversas vezes as necessidades dos filhos, adotando dieta desregrada e atentado contra o direito à saúde e ao livre desenvolvimento da personalidade, os genitores demonstram total incompatibilidade com o exercício do poder familiar, dando ensejo, em situações-limite e devidamente encampadas por laudos periciais, à atuação do Ministério Público para tutelar os interesses de crianças/adolescentes por meio de demandas de internação compulsória ou, em último caso, destituição do poder familiar.

\section{Considerações finais}

A questão da obesidade e seu tratamento vem assumindo especial interesse da comunidade científica, sobretudo nos casos em que os sujeitos envolvidos não têm capacidade jurídica plena (crianças e adolescentes).

É preciso atentar para o fato de que o corpo assume não só um papel fundamental no modo como "vivenciamos" a realidade, mas também na construção do sentido do "Eu". Em outras palavras, o reino do tamanho do corpo não pode ser visto exclusivamente sob o pálio médico-científico, mas deve ser vislumbrado também sob uma perspectiva humanista, que compreenda a pessoa humana como um fim em si mesma.

Sob essas premissas, o presente estudo permite concluir não só acerca da existência de um "direito a ter qualquer tamanho corporal" - enquanto manifestação do direito ao livre desenvolvimento da personalidade -, mas também que esse direito é dotado de limites: ao verificar situações de obesidade mórbida que efetivamente impeçam crianças e adolescentes de terem uma vida digna, com acúmulo anormal de gordura corporal que atinja graus capazes de afetar a saúde, sem que contem com a efetiva supervisão dos genitores, torna-se necessária a intervenção do Ministério Público, com a propositura, segundo as peculiaridades do caso, de demandas de internação compulsória ou de destituição do poder familiar.

Em suma, a comunidade médico-jurídica possui um considerável conhecimento acumulado sobre a temática da obesidade. Ela também possui a criatividade e a habilidade para oferecer novas soluções para problemas que assolam a obesidade infantil. Mas a comunidade médico-jurídica precisa desejar correr os riscos associados com a exploração de novos horizontes. Não é certo quão longe os investimentos nesses riscos nos levarão. Mas é certo que não iremos a lugar algum se os evitarmos. 


\section{Referências}

ADAMS, Kenneth F. et al. Overweight, Obesity, and Mortality in a Large Prospective Cohort of Persons 50 to 71 Years Old. New England Journal of Medicine, v. 355, p. 763-778, 2006.

ALEXY, Robert. Teoria dos Direitos Fundamentais. Tradução: Virgílio Afonso da Silva. São Paulo: Malheiros, 2008.

AFONSO DA SILVA, Virgílio. Direitos Fundamentais - Conteúdo Essencial, Restrições e Eficácia. São Paulo: Malheiros Editores, 2011.

AFONSO DA SILVA, Virgílio (org.). Interpretação constitucional. São Paulo: Malheiros, 2005.

AFONSO DA SILVA, Virgílio. Princípios e regras: mitos e equívocos acerca de uma distinção. Revista Latino-Americana de Estudos Constitucionais, p. 607-630, 2003.

AFONSO DA SILVA, Virgílio; TERRAZAS, Fernanda Vargas. Claiming the Right to Health in Brazilian Courts: The Exclusion of the Already Excluded? Law \& Social Inquiry, v. 36, p. 825-853, 2011.

ANDERSON, Sarah E. et al. Adolescent obesity and risk for subsequent major depressive disorder and anxiety disorder: Prospective evidence. Psychosomatic Medicine, v. 69, n. 8, p. 740-747, 2007.

ASCENSÃO, José de Oliveira. Pessoa, direitos fundamentais e direito da personalidade. Revista Mestrado em Direito, Osasco, ano 6, n. 1, p. 145-168, 2006.

BIRCH, Lipps L.; VENTURA, Alison K. Preventing childhood obesity: What works? International Journal of Obesity, v. 33, p. 74-81, 2009.

COSTA, Rafael de Oliveira. Segurança Jurídica e Hermenêutica Constitucional: Horizontes Jusfilosóficos da Previsibilidade das Decisões Judiciais. 2009. 183 p. Dissertação (Mestrado em Direito) Faculdade de Direito, Universidade Federal de Minas Gerais, Belo Horizonte, 2009.

DEV, Dipti A. et al. Risk factors for overweight/obesity in preschool children: an ecological approach. Childhood Obesity, v. 9, n. 5, p. 399-408, 2013.

GOODMAN, Elizabeth; WHITAKER, Robert C. A Prospective Study of the Role of Depression in the Development and Persistence of Adolescent Obesity. Pediatrics, v. 110, n. 3, 497-504, 2002.

GU, Dongfeng et al. Body weight and mortality among men and women in China. JAMA, v. 295, n. 7, p. 776-783, Feb. 2006.

HASLER, Gregor et al. Depressive symptoms during childhood and adult obesity: the Zurich Cohort Study. Molecular Psychiatry, v. 10, p. 842-850, 2005.

HEDLEY, Allison A. et al. Prevalence of Overweight and Obesity Among US Children, Adolescents, and Adults, 1999-2002. JAMA, v. 291, n. 23, p. 2847-2850, 2004.

HEIDEGGER, Martin. Ser e Tempo. Tradução: Márcia de Sá Cavalcante Schuback. Petrópolis: Vozes, 2006. 
NEAD, Karen G. et al. Overweight Children and Adolescents: A Risk Group for Iron Deficiency. Pediatrics, v. 114, n. 1, p. 104-108, 2004.

KIRKLAND, Anna. Think of the Hippopotamus: Rights Consciousness in the Fat Acceptance. Law and Society Review, v. 42, p. 397-425, 2008.

KOPLAN, Jeffrey. Progress in Preventing Childhood Obesity: How Do We Measure Up? Washington-DC: National Academies Press, 2007.

LYTLE, Leslie A.; KUBIK, Martha Y.; PERRY, Cheryl L. Influencing healthful food choices in school and home environments: Results from the TEENS study. Preventive Medicine, v. 43, p. 8-13, 2006.

MEGALE, Maria Helena Damasceno e Silva. Fenomenologia e Hermenêutica Jurídica. Belo Horizonte: Fundação Valle Ferreira, 2007.

NIEMAN, Peter; LEBLANC, Claire M. A. Healthy Active Living and Sports Medicine Committee Psychosocial aspects of child and adolescent obesity. Pediatric Child Health, v. 17, n. 4, p. 205-206, 2012 .

OLIVEIRA, Márcio Luís de. A Constituição Juridicamente Adequada: transformações do constitucionalismo e atualização principiológica dos direitos, garantias e deveres fundamentais. Belo Horizonte: Arraes, 2013.

PEREIRA, Caio Mario da Silva. Instituições de direito civil. 22. ed. Rio de Janeiro: Forense, 2008.

RAMACHANDRAN, Gowri. Against the Right to Bodily Integrity: Of Cyborgs and Human Rights. Denver University Law Review, v. 87, 2009.

SARLET, Ingo Wolfgang. Dignidade da Pessoa Humana e Direitos Fundamentais na Constituição de 1988. 7. ed. Porto Alegre: Advogado, 2009.

GARRAHAN, Shauneen M.; EICHNER, Andrew W. Tipping the Scale: A Place for Childhood Obesity in the Evolving Legal Framework of Child Abuse and Neglect. Yale J. Health Policy, Law \& Ethics, 2012.

SCHNEIDER, Elizabeth M. et al. The Associations of Parenting Factors with Adolescent Body Mass Index in an Underserved Population. Journal of Obesity, p. 618-715, 2013.

SILVA, Virgílio Afonso da; TERRAZAS, Fernanda Vargas. Claiming the Right to Health in Brazilian Courts: The Exclusion of the Already Excluded? Law \& Social Inquiry, v. 36, p. 825-853, 2011.

TIROSH, Yofi. The Right to Be Fat. Yale Journal of Health Policy, Law and Ethics, New Heaven, v. XII, tomo 2, p. 264-335, 2012.

WANG, Fan; VEUGELERS, Paul. Self-esteem and cognitive development in the era of the childhood obesity epidemic. Obesity Reviews, v. 9, n. 6, p. 615-23, 2008.

WHETSTONE, Lauren M.; MORRISSEY, Susan L.; CUMMINGS, Doyle M. Children at risk: the association between perceived weight status and suicidal thoughts and attempts in middle school youth. Journal of School Health, v. 77, n. 2, p. 59-66 e 98-99, 2007. 